\title{
5 Research Square

\section{Impact of the COVID-19 Pandemic and Associated Lockdown Measures on the Management, Health and Behaviour of the Cystic Fibrosis Population in France During 2020 (MUCONFIN)}

Nadia Oubaya

Centre Hospitalier Universitaire Henri-Mondor

Thibaut Pombet

Paris-Est Créteil University

Celine Delestrain

Hôpital Intercommunal de Créteil

Natascha Remus

Hôpital Intercommunal de Créteil

Benoit Douvry

Hôpital Intercommunal de Créteil

Dominique Grenet

Hôpital Foch

\section{Harriet Corvol}

Hôpital Armand-Trousseau

\section{Guillaume Thouvenin}

Hôpital Armand-Trousseau

\section{Virginie Prulière-Escabasse}

Hôpital Intercommunal de Créteil

Hakima Mounir

Paris-Est Créteil University

Dominique Argoud

Paris-Est Créteil University

\section{Cédric Fretigne}

Paris-Est Créteil University

\section{Laurence Costes}

Paris-Est Créteil University

\section{Marie-Pierre Mackiewicz}

Paris-Est Créteil University

\section{Camille Jung}




\section{Laitissia Ahamada}

Hôpital Intercommunal de Créteil

\section{Sophie Lanone}

Paris-Est Créteil University

\section{Bernard Maitre}

Hôpital Intercommunal de Créteil

\section{Anne-Cécile Bégot}

Paris-Est Créteil University

Ralph Epaud ( $\sim$ ralph.epaud@chicreteil.fr)

Hôpital Intercommunal de Créteil

\section{Research Article}

Keywords: Cystic Fibrosis, Healthcare, COVID-19, Lockdown

Posted Date: January 6th, 2022

DOl: https://doi.org/10.21203/rs.3.rs-1187450/v1

License: (c) (i) This work is licensed under a Creative Commons Attribution 4.0 International License. Read Full License 


\section{Abstract}

\section{Background}

Most of the studies on cystic fibrosis (CF) focused on SARS-CoV-2 prevalence and suggested a low incidence of infection in this population We aimed to assess in cystic fibrosis (CF) patients the impact on healthcare access, health, and behaviour of the pandemic and associated lockdown measures implemented in May 2020 in response to the first wave of SARS-CoV-2 infection.

\section{Methods}

A national questionnaire opened online from May 10th, 2020 to June 11th, 2020 was completed by 751 CF-patients, aged 14 years and over. It comprised questions about access to healthcare, anxiety and depression, smoking, alcohol, drug and psychotropic drug consumption, adherence to CF treatment, and constraints. A semi-structured comprehensive interview was performed no later than one month after the end of the lockdown in 15 CF-patients.

Results

The mean age of the population was 28 [IQR 20-37] years old. More than $75 \%$ of in-person consultations scheduled during the lockdown were cancelled and $27 \%$ were postponed, but telehealth consultations were proposed and accepted in almost $40 \%$ of cases. More than $75 \%$ of the scheduled physiotherapy sessions were cancelled and replaced mainly by self-drainage. Annual follow-up clinic visits were consistently postponed whereas required hospitalizations at CF centres for exacerbation were maintained in most cases. While $43 \%$ CF-patients had signs of anxiety, $51 \%$ presented symptoms of depression, both associated with increased use of psychotic medications and inversely correlated to COVID-19 prevalence. Among the lower and lower middle classes, very little medical information was obtained or requested by the patient, participation to sports or other activities was low, while excessive home confinement and isolation were more frequent. In contrast, in the upper middle and upper classes, individuals solicitated help to their CF centre, had more physical activities, and maintained contact with friends or families.

\section{Conclusion}

The first lockdown in France had only minimal impact on the management care of CF-patients but was associated with increased symptoms of anxiety and depression, together with behavioural changes that varied with social class

\section{Introduction}

The discovery of a new form of pneumonia in early December 2019 in Wuhan, Hubei Province, followed by the rapid spread of the virus in China and across all continents, has drastically changed the face of healthcare throughout the world[1]. By March 2020, France had the second highest number of SARS-CoV- 
2 infections and the greatest number of deaths in Europe, which led the French authorities to initiate a strict lockdown from March 17th to May 10th, 2020.

Cystic fibrosis (CF) is the most common autosomal recessive disease that leads to early mortality in Caucasians, and affects around 7500 patients in France[2]. Lung disease remains the major cause of morbidity and mortality in $\mathrm{CF}$, with a progressive decline of lung function due to a vicious cycle of airway infections and inflammation[3]. In France, the national newborn screening program, established in 2002, has been associated with the accreditation of specialized CF care centres (CRCM: Centre de Ressources et de Compétences de la Mucoviscidose). These centres are dedicated to the close follow-up of CFpatients from diagnosis to adulthood[4]. The implementation of standard protocols and the centralization of services delivered by highly trained, multidisciplinary teams have contributed to prevention of the progressive deterioration of respiratory function described in the older CF literature.

The impact of SARS-CoV-2 infection on these patients was uncertain. Nevertheless, co-morbidities such as underlying respiratory problems were identified as risk factors for severe COVID-19 disease, and given the serious respiratory complications caused by viral infections $[5,6]$, CF-patients were expected to be at higher risk of severity. Surprisingly, the first reports in Europe suggested a lower impact overall than initially feared for these patients[7, 8], but

it rapidly became evident that the impact of COVID-19 on CF-patients was not limited to the consequences of the infection but also resulted from the necessary measures taken to limit the spread of the disease such as isolation, quarantine, social distancing and community containment. Moreover, hospitals had to profoundly change their procedures and almost entirely focus on the care of COVID-19 patients. This forced transformation was at the expense of other critical functions, including the management of chronic diseases such as CF.

In this context, the present study more specifically addresses the impact of the COVID-19 pandemic and associated lockdown measures on the management, health, and behaviours of CF-patients during the first wave of COVID-19 in France. Our results are based on a national survey from patients over 14 years old using web questionnaires. This quantitative study was completed by a qualitative study including representative CF-patients who were interviewed by social science and humanities researchers.

\section{Methods}

\section{Design and population}

This is a French national multicentre cross-sectional study using mixed methods (quantitative and qualitative) that enrolled CF-patients 14 years-old and over. The inclusion criteria were CF-patients with a chloride sweat test $>60 \mathrm{mEq} / \mathrm{L}$ and/or 2 CFTR gene variants, followed at one of the French CF reference centres (CRCM), covered by the national health insurance system, and willing to participate to the study (non-opposition from the patient if aged $>18$ years and non-opposition from the parents if the patient is $<18$ years old). 


\section{Data collection}

CF-patients had to fill out an online questionnaire. Patients could access the questionnaire using a generic link from May 10th, 2020 to June 11th, 2020. It comprised questions about sociodemographic, access to healthcare during lockdown, anxiety and depression, smoking, alcohol, drug and psychotropic drug consumption, adherence to CF treatment, fear and knowledge about COVID-19 and constraints due to lockdown.

The questionnaire was complemented by a semi-structured comprehensive interview $[9,10]$ performed by Visio conference between the end of the lockdown and up to one month later. A sample of 16 CF-patients representative of the French population according to the data produced by the French Cystic Fibrosis Registry was selected from three centres: mixed (Créteil), paediatric (Trousseau, Paris) and adult (Foch, Suresnes).

\section{Outcomes}

\section{Primary outcome}

The primary outcome was the reduction to healthcare access as defined by cancellation or rescheduling of consultations (with the doctor or physiotherapist) by the healthcare professional or by the patient, cancellation by the patient of telehealth, cancellation or rescheduling by the hospital or by the patient of hospitalisations (planned or not) and change in the route of administration of antibiotics (oral vs. intravenous).

\section{Secondary outcomes}

The secondary outcomes included: 1) Compliance to treatment plans and airway clearance as assessed by the adherence score[11]; 2) Assessment of anxiety and depression using the 7-Item Generalized Anxiety Disorder Scale (GAD-7)[12] and the validated French version of the 9-item Patient Health Questionnaire Depression Scale (PHQ-9)[13, 14]; 3) Assessment of quality of life using the specific CF CFQ 14 questionnaire adapted to the context of lockdown; 4) Knowledge and concern about COVID-19 and the declared prevalence of COVID-19 infections suspected or confirmed; 5) Impact of the lockdown on social inequality.

\section{Data analysis}

The results were reported according to the STROBE guidelines for observational studies. Sociodemographic characteristics of the population were described using numbers (percentages) for categorical variables, mean \pm standard deviation (SD) or median [interquartile range (IQR)], as appropriate, for quantitative variables. The proportion of patients with a reduction in healthcare access during lockdown was described by percentage and $95 \%$ confidence interval. Criteria from validated questionnaires (quality of life, compliance, anxiety) were compared with historical values in the literature from comparable populations using Chi2 tests for qualitative variables and Student's t tests for 
quantitative variables. Stratified analyses were carried out according to age (child, adult) and COVID-19 status. All significance tests were two-tailed, and the threshold for statistical significance level was set to 5\%. All analyses were performed with Stata software (v16.0 StataCorp. 2019. Stata Statistical Software: Release 16. College Station, TX: StataCorp LLC.) and R software (R Core Team, R Foundation for Statistical Computing, Vienna, Austria, 2020).

\section{Ethics}

This study was carried out in accordance with the Declaration of Helsinki, good clinical practice, and French legislation on clinical research. The study was approved by the Ethics Committee (Comité de Protection des Personnes (CPP) Est, 15/05/2020) (CPP N²0.05.11). Informed consent was obtained from all patients $>18$ years old and from parents for patients $<18$ prior to inclusion. ClinicalTrials.gov Identifier: NCT04463628

\section{Results}

\section{Characteristics of the studied population}

Baseline characteristics and geographic location of the study population are summarized in Table 1. Within a month, we collected 751 completed questionnaires, with 725 being exploitable (Figure S1). The mean age of the studied population was 28 years-old [IQR 20-37], with a predominance of women (62.5 $\%)$. Students were highly represented ( $28 \%$ ), and among patients of working age, the private sector was the most represented (22\%). Homemakers represented $8 \%$ of the CF-patients. For qualitative analysis, 16 CF-patients were solicited, and 15 were interviewed.

\section{Consequences of the COVID-19 pandemic and associated lockdown measures on healthcare organisation}

More than $75 \%$ of consultations scheduled during the lockdown were cancelled (Table 2; Table 3interview comments verbatim A5, A9). However, telehealth was alternatively proposed and accepted in almost $40 \%$ of cases, whereas $27 \%$ of scheduled consultations were postponed. Overall, $87 \cdot 7 \%$ CFpatients [CI 95\%: 84.1; 90.5] were offered access to consultations. The trend varied depending on the geographic location (Table S1) (Grand Est region (64.0\%) vs. rest of the territory (89.2\%); $p<0.001$ ) or the age of patients (under $18(95.2 \%)$ vs. adults $(86.3 \%) ; p=0.05)$. More than $75 \%$ of the scheduled physiotherapy sessions were cancelled (mostly by the physiotherapist), and only few telehealth or online programs were proposed (Table $3, \mathrm{~A} 1$ ), resulting in the use of self-drainage in a significant number of cases (Table 3, B1). While some patients indicated that they found it difficult to be away from their physiotherapists during the confinement (Table 3, B7), especially when they needed reassurance from these professionals (Table 3: B1), others indicated that they benefited from the advice given by their centre physiotherapist or that they initiated new activities such as yoga or home exercise to stay active (Table 3, B2-B6). As predicted, the routine annual follow-up visits were consistently cancelled or postponed in most cases. In contrast, hospitalizations required for symptom exacerbation were 
maintained in most of the cases in the CF centres. The required intravenous administration of antibiotics was performed at home in more than $75 \%$ of patients. Although the qualitative questionnaire did not specifically include any questions regarding this specific topic, CF-patients who underwent qualitative interviews had no difficulty getting the needed prescription drugs during the lockdown period (Table 3 , C6).

\section{Health Impact of the COVID-19 pandemic and associated lockdown measures}

\section{Concerns about COVID-19.}

Numerous CF-patients reported that their centre initially provided insufficient information about specific risk of COVID-19 for CF-patients (Table 3 A3, A4, C9). Nevertheless, this improved overtime through interactions with physicians and coordinating nurses or through direct information from medical institutions, such as via WhatsApp groups or email diffusion (Table 3: A5-6, A8-12, A16, A18). As a result, answers to the questionnaires showed that CF-patients had significant knowledge about the SARS-CoV-2 infection. Nonetheless, $65 \%$ of CF-patients believed that they were at higher risks of COVID-19, and $85 \%$ thought that they were more likely to have COVID-19 complications (Table S2; Table 3; A2, A14, C4, C16). This contrasted with the small number of CF-patients who were infected, as only 74 among those responding to the questionnaire had symptoms suggestive of COVID-19 (10\%), and among the 20 who were tested, only one was positive. Individuals with CF were less worried about the risks from their treatment, as only 9.5 and $14 \%$ considered that CF medications were putting them at greater risk of COVID-19 or COVID-19 complications, respectively (Table S2). Unexpectedly, CF-patients living in the Southwest of France (where low case numbers were reported at the time of the first wave) were significantly more likely to be very concerned about becoming ill with SARS-CoV-2 infection compared to those living in the Northeast of France (with high prevalence of SARS-CoV-2 cases at the time of the first lockdown) (Figure 1). On a constraint scale from 1 to 10, with 1 being "very low" and 10 being "very high", the constraint of barrier measures was 2 [0-5 IQR] while that from the lockdown was 5 [2-8 IQR]. Results are shown for each of the French regions in Figure 1.

\section{Psychological Consequences of the COVID-19 Pandemic and Associated Lockdown Measures}

The majority of patients $(418 / 703 ; 59.5 \%)$ did not feel differently about their health status compared to three months earlier, whereas 161 (22.9\%) felt that their health improved and 124 (17.6\%) reported health degradation. Analysis of the 725 validated questionnaires (Table 4) showed that $43 \%$ of the CF-patients had signs of anxiety based on the GAD-7 questionnaire, with 26,11 and $43 \%$ having mild, moderate or severe anxiety, respectively, whereas $51 \%$ presented signs of depression based on the PHQ-9 questionnaire, with $30,15,4$, and $2 \%$ having mild, moderate, moderately severe and severe depression, respectively. These anxiety symptoms were also reported in interviews and were mostly related to the perceived higher risk of COVID-19 for CF-patients (Table 3; A5, A13, A15, B2). Anxiety and depression prevalence (mild, moderate or severe) was lower in the 14-18 years-old group compared to older CFpatients (anxiety: $32 \cdot 5 \%$, [14-18] vs. $43.3 \%$ [18-25], 48.4\%, [25-35] and 43.0\% $\geq 35 ; p=0.049$; depression: $44 \cdot 7 \%[14-18]$ vs. $55.6 \%$ [18-25], $56.1 \%$ [25-35] and $46 \cdot 6 \% \geq 35 ; p=0.066)$. Furthermore, the prevalence and 
severity of anxiety and depression were inversely correlated with the prevalence of COVID-19 cases during the first lockdown (Figure 1). In line with the increase in anxiety and depression with age, a significant increase in smoking, consumption of alcohol and psychotic medications, and sleep disorders was found in older patients (Table 4). Assessing treatment adherence using a score of compliance/ 6 indicated a median [IQR] score of $1.0(1 \cdot 0-3 \cdot 0)$ with $21 \%$ of the CF-patients having good compliance, $53 \%$ minor noncompliance and $25 \%$ noncompliance (Table 5). Interestingly, a significant difference was observed with age, with a median score of compliance/ 6 of $1 \cdot 0$ [0.0-2.0] in older patients ( $>35$ years old) as compared with that in younger patients $(1.0$ [1.0-3.0] for $<18,2.0$ [1.0-2.5] for $18-25$ and 2.0 [1-0-3.0] for 25-35 years old; $p=0.0004$ ), contrasting with the higher percentage of "good compliance" in the older group ( $>35$ years old) with $33.5 \%$, more than double that observed in younger patients $(15.6$ for $<18,15.3$ for $18-25,15 \cdot 3$ for $25-35$ years old, $p<0 \cdot 001$ ) (Table 5). Moreover, noncompliance was associated with the presence of anxiety $(32.8 \%$ in patients with anxiety vs. $20.1 \%$ in the non-anxious group; $p<0.0001)$ or depression symptoms (32.3\% in patients with depression symptoms vs. $18.4 \%$ in the non-depressive group; $p<0.0001)$.

\section{Social inequalities during COVID-19 pandemic and associated lockdown}

Among the working population, 131 (44.9\%) stopped working, 91 (31.2\%) reduced their hours of work, and 70 (24.0\%) worked more than before lockdown. Regarding the place of work, 176 (81.5\%) worked from home, 29 (13.4\%) were already home-based prior to the lockdown and $11(5 \cdot 1 \%)$ were still going to their place of work. Among the students, 192 (96.0\%) remained schooled.

Based on content analysis, differences by social categories among the 3 major themes of concern emerged from the interviews (Table 3; A-C). First, regarding the relationship to medical institutions, we observed that among the working and lower-middle social categories, very little information and guidance in relation to the COVID-19 pandemic was obtained or requested by the patients (Table 3; A1). These patients felt "lost" (Table 3; A2-3), forced to manage their care on their own, and plagued by feelings of anxiety (Table 3; A5-7). In the upper-middle and upper categories, some CF-patients did not hesitate to call their CF centre several times for information, providing reassurance (Table 3: A13). Second, regarding the relationship to sport and physical therapy (Table 3; B), CF-patients from the lower-middle category reported doing little or no sport, either before confinement or after (Table 3; B7). Not moving was perceived in this group as reinforcing the feeling of being alone and isolated (Table 3; B4). These CFpatients attested to their difficulty being away from their physiotherapists during lockdown (Table 3: B1B7). In CF-patients from more privileged categories status, the confinement was an opportunity to find new activities to practice physical exercise (Table 3; B9-B10). The third theme that emerged from the interviews related to psychosocial adjustment to COVID-19 pandemic and associated lockdown measures. CF-patients from the lowest social categories mostly over-confined themselves, with some not getting out at all during the lockdown (Table 3; C1-2, C6, C10-12). In contrast, some CF-patients belonging to the upper-middle and upper categories declared that they did not take additional precautions during the confinement (Table 3; $14-15$ ) but tried to meet outside and for some of them, even had get-together between neighbours (Table 3; 16 ). 


\section{Discussion}

In this qualitative and quantitative study, we show that the first lockdown did not significantly impact care as provided by CF centres. However, despite the low number of CF-patients diagnosed with COVID-19, they developed significant worsening symptoms of anxiety and depression during the first lockdown.

In France, following the introduction of lockdown measures, hospitals were asked to postpone consultations and surgeries considered to be non-urgent. In the present study, almost $2 / 3$ of the consultations were maintained or replaced by telehealth and almost all necessary hospitalizations occurred (mostly in their affiliated centres). Consultations for physiotherapy were more affected as they were cancelled by many CF-patients. However, self-drainage was used as a substitute as it is a common practice in CF. Finally, intravenous antibiotic treatments were mostly performed at home without delay, which is also a common practice in CF-patients. This low impact of the first wave of the pandemic on CF care in France, but also in other countries with similar organization, is likely due to the availability of CF Centres that were able to adjust and initiate rapid changes in care delivery $[4,15]$. This may have facilitated the preservation of almost optimal care for most CF-patients, even though adult pulmonary specialists were not readily available due to their taking care of COVID-19 patients.

In the absence of available vaccines, social distancing is one of the main tools for preventing the transmission of SARS-CoV-2. As CF increases the risk of viral and bacterial respiratory infections, CFpatients are acutely aware of the benefits of practicing social distancing[16, 17]. This can explain that constraint from this barrier measure was reported to be low in our study. In contrast, more patients were affected by the restrictions from the lockdown. One common observation in patients with chronic disease was an increase in anxiety and depression symptoms. In the general population, results from surveys conducted early in the COVID-19 pandemic (March-June 2020) have shown increased prevalence of mental health symptoms, especially among young adults[18-21]. People with CF are two to three times more likely to experience depression, anxiety, or both, compared to people in the general population[22] $[23,24]$. In France, data from the CF registry identified about $8 \%$ of patients with depression symptoms (diagnosed or followed), increasing with age, from $4 \%$ in adolescents to $16 \%$ in subjects older than 35 years old[2]. The results of our study suggest that anxiety and depression symptoms were significantly increased in CF-patients during the first lockdown in France, and an increase with age was also observed. This resulted in an increase in sleep disorders, together with increased alcohol and psychotropic medication use. Surprisingly, anxiety and depression symptoms were more frequent in geographic areas where COVID-19 prevalence was low, while they were less important in areas with higher prevalence, suggesting that these symptoms do not correlate with the real risk of disease in this population.

The impact of COVID-19 and associated measures on mental disorders during the lockdown is not limited to CF-patients. Similar trends were reported in patients with COPD during lockdown with significantly intensified symptoms and disorders of mental illness such as fear, anxiety and depression[25].

Interestingly, this was associated with increased adherence to using their preventive inhalers in more than one fourth of the subjects[26]. Poor treatment adherence is common in $\mathrm{CF}[27,28]$ and is likely to be 
worsened by decrease access to healthcare caregivers/structures, increased fears of SARS-CoV-2 contamination when having to get medications in pharmacies or increased anxiety/depression symptoms. Smith et al. reported that depression symptoms in children were significantly associated with lower rates of adherence to airway clearance, whereas there was no significant association between patient's adherence to medical treatment/airway clearance and the PHQ-9 or GAD-7 scores of patients in the Turkish study[23]. In our study, the presence of anxiety/depression symptoms during lockdown was associated with poor treatment adherence. A trend similar to that of COPD (disease with higher median age) was observed with only $20 \%$ noncompliance; however, this did not seem to be due to increased anxiety or depressive symptoms.

During the SARS-CoV-2 pandemic, it has been emphasized that the most precarious populations were more affected by COVID-19, notably because they accumulate several factors that cause the spread of the virus[29]. Among them, three factors, often cumulative, reinforce social inequalities in healthcare: differences in access to care, inequalities in exposure risk and differences in vulnerability to disease[30]. Interestingly, these factors were of moderate impact in our study across social categories. The very tight relationship between CF-patients and their CF healthcare team at the centre may have helped maintain good level of care independently of social disparities, as there are no charges for the patient, even during the health crisis. In terms of access to care, according to the French Health Insurance registry, practice visits declined by $40 \%$ and specialist visits by $50 \%$ in the general population, while a significant decrease in access to care for CF-patients was not observed, even in the context of precarity.

The present study has several limitations. The questionnaires were available online with a generic link, and we could not verify that all responders were CF-patients $>14$ years old. However, an information letter was provided with the questionnaire, explaining the selection criteria, and requiring for the responders to enter their age on the questionnaire, which prevented those under 14 to fill out the remaining questionnaire. Our study has also some strengths. This was a national multicentre study with participating patients from all CF centres in France. The short duration of the recruitment period avoided bias in the context of a very rapidly evolving pandemic situation. Furthermore, the study used both quantitative and qualitative methodologies, which helped understanding all aspects of the COVID-19 pandemic and the resulting lockdown.

In conclusion, COVID-19 pandemic and associated lockdown measures in France had only minimal impact on the care management of CF-patients. The adaptability of well-structured CF centres in establishing short-term measures during the pandemic may be a model for the development of similar organization for other chronic lung diseases. However, the higher risk for anxiety and depression in CFpatients reported here needs to be considered when developing new models for care during future sanitary crisis.

\section{Declarations}


- Ethics approval and informed consent to participate: All authors gave informed consent for publication, confirmed that they had full access to all the data in the study, have approved the final draft of the manuscript and accepted the responsibility to submit for publication.

- Availability of data and materials: All data presented in this manuscript, including the developed questionnaire, is available from the corresponding author upon reasonable request.

- Competing interests: The authors declare no competing interests.

- Funding: None

- Authors' contributions: NO performed the statistical analysis, wrote the original draft of the manuscript, and has verified all data. TP wrote and reviewed the manuscript and participated to the quantitative interviews and analysis. $C D$ designed the study, wrote and reviewed the manuscript, and has verified all data. NR, BD, DG, HC, GT and VPE designed the questionnaire and reviewed the manuscript. HM, DA, CF, LC, MPM performed and analyzed the quantitative interviews. CJ and LA designed the statistical analysis strategy and scripts for the statistical analyses. BM, SL, ACB and RE conceived and designed the study, reviewed the manuscript, and verified all data. RE is the principal investigator of the MUCONFIN study.. RE is the study guarantor and attests that all listed authors meet authorship criteria and that no others meeting the criteria have been omitted. NO, TP and $C D$ contributed equally to the study.

- Acknowledgements: We are very grateful to the patients who took time to fill in questionnaires or undergo interviews. We are grateful to National Clinical Research Programme) (PNRC) and the Clinical Research Centre (CRC) of the CHIC for their valuable help in the elaboration of the questionnaires. We thank "Vaincre La Mucoviscidose", the Filière MUCOVICIDOSE-CFTR, the CHIC communication department and all the CRCMs in France for their support and their assistance in the distribution of the questionnaires. We are grateful to Cécile Hoffart for clinical research coordination assistance, Martine Torres (manuscript) and Sequoya Frey (verbatims) for English editing assistance. This study was supported by the REMEDIA project funded by the European Union's Horizon 2020 Research and Innovation Program under grant agreement No 874753.

\section{References}

1. Zhu H, Wei L, Niu P: The novel coronavirus outbreak in Wuhan, China. Global Health Research and Policy 2020, 5(1):6.

2. Registre français de la mucoviscidose - Bilan des données 2019. In.: Vaincre la Mucoviscidose; 2021.

3. Elborn JS: Cystic fibrosis. Lancet 2016, 388(10059):2519-2531.

4. Colombo C, Littlewood J: The implementation of standards of care in Europe: state of the art. $J$ Cyst Fibros 2011, 10 Suppl 2:S7-15. 
5. Viviani L, Assael BM, Kerem E, group EHNs: Impact of the A (H1N1) pandemic influenza (season 2009-2010) on patients with cystic fibrosis. J Cyst Fibros 2011, 10(5):370-376.

6. Yang J, Zheng Y, Gou X, Pu K, Chen Z, Guo Q, Ji R, Wang H, Wang Y, Zhou Y: Prevalence of comorbidities and its effects in patients infected with SARS-CoV-2: a systematic review and metaanalysis. Int $J$ Infect Dis 2020, 94:91-95.

7. Corvol H, de Miranda S, Lemonnier L, Kemgang A, Reynaud Gaubert M, Chiron R, Dalphin ML, Durieu I, Dubus JC, Houdouin V et al: First Wave of COVID-19 in French Patients with Cystic Fibrosis. $J$ Clin Med 2020, 9(11).

8. Bain R, Cosgriff R, Zampoli M, Elbert A, Burgel PR, Carr SB, Castanos C, Colombo C, Corvol H, Faro A et al: Clinical characteristics of SARS-CoV-2 infection in children with cystic fibrosis: An international observational study. J Cyst Fibros 2021, 20(1):25-30.

9. Kaufmann J: L'entretien compréhensif, 4éme édition edn; 2016.

10. Cardon D: <i>L'entretien compréhensif</i> (Jean-Claude Kaufmann). Réseaux Communication Technologie - Société 1996:177-179.

11. Girerd X, Hanon O, Anagnostopoulos K, Ciupek C, Mourad JJ, Consoli S: Evaluation de l'observance du traitement antihypertenseur par un questionnaire: mise au point et utilisation dans un service specialise. Presse Med 2001, 30(21):1044-1048.

12. Spitzer RL, Kroenke $K$, Williams JB, Lowe $B$ : A brief measure for assessing generalized anxiety disorder: the GAD-7. Arch Intern Med 2006, 166(10):1092-1097.

13. Kroenke K, Spitzer RL, Williams JB: The PHQ-9: validity of a brief depression severity measure. $J$ Gen Intern Med 2001, 16(9):606-613.

14. Negeri ZF, Levis B, Sun Y, He C, Krishnan A, Wu Y, Bhandari PM, Neupane D, Brehaut E, Benedetti A et al: Accuracy of the Patient Health Questionnaire-9 for screening to detect major depression: updated systematic review and individual participant data meta-analysis. BMJ 2021, 375:n2183.

15. Davies J: The coronavirus pandemic has forced rapid changes in care protocols for cystic fibrosis. Nature 2020, 583(7818):S15.

16. Surette MG: The cystic fibrosis lung microbiome. Ann Am Thorac Soc 2014, 11 Suppl 1:S61-65.

17. Kiedrowski MR, Bomberger JM: Viral-Bacterial Co-infections in the Cystic Fibrosis Respiratory Tract. Front Immunol 2018, 9:3067.

18. McKnight-Eily LR, Okoro CA, Strine TW, Verlenden J, Hollis ND, Njai R, Mitchell EW, Board A, Puddy $\mathrm{R}$, Thomas C: Racial and Ethnic Disparities in the Prevalence of Stress and Worry, Mental Health 
Conditions, and Increased Substance Use Among Adults During the COVID-19 Pandemic - United States, April and May 2020. MMWR Morb Mortal Wkly Rep 2021, 70(5):162-166.

19. Czeisler ME, Lane RI, Petrosky E, Wiley JF, Christensen A, Njai R, Weaver MD, Robbins R, FacerChilds ER, Barger LK et al: Mental Health, Substance Use, and Suicidal Ideation During the COVID-19 Pandemic - United States, June 24-30, 2020. MMWR Morb Mortal Wkly Rep 2020, 69(32):1049-1057.

20. Vahratian A, Blumberg SJ, Terlizzi EP, Schiller JS: Symptoms of Anxiety or Depressive Disorder and Use of Mental Health Care Among Adults During the COVID-19 Pandemic - United States, August 2020-February 2021. MMWR Morb Mortal Wkly Rep 2021, 70(13):490-494.

21. Meherali S, Punjani N, Louie-Poon S, Abdul Rahim K, Das JK, Salam RA, Lassi ZS: Mental Health of Children and Adolescents Amidst COVID-19 and Past Pandemics: A Rapid Systematic Review. Int J Environ Res Public Health 2021, 18(7).

22. Quittner AL, Goldbeck L, Abbott J, Duff A, Lambrecht P, Sole A, Tibosch MM, Bergsten Brucefors A, Yuksel $\mathrm{H}$, Catastini $\mathrm{P}$ et al: Prevalence of depression and anxiety in patients with cystic fibrosis and parent caregivers: results of The International Depression Epidemiological Study across nine countries. Thorax 2014, 69(12):1090-1097.

23. Mursaloglu HH, Yilmaz Yegit C, Ergenekon AP, Gokdemir Y, Eralp EE, Karakoc F, Nasr SZ, Karadag BT: Screening of depression and anxiety in adolescents with cystic fibrosis and caregivers in Turkey by PHQ-9 and GAD-7 questionnaires. Pediatr Pulmonol 2021, 56(6):1514-1520.

24. Smith BA, Modi AC, Quittner AL, Wood BL: Depressive symptoms in children with cystic fibrosis and parents and its effects on adherence to airway clearance. Pediatr Pulmonol 2010, 45(8):756-763.

25. Yohannes AM: COPD patients in a COVID-19 society: depression and anxiety. Expert Rev Respir Med 2021, 15(1):5-7.

26. McAuley H, Hadley K, Elneima O, Brightling CE, Evans RA, Steiner MC, Greening NJ: COPD in the time of COVID-19: an analysis of acute exacerbations and reported behavioural changes in patients with COPD. ERJ Open Res 2021, 7(1).

27. Hoo ZH, Totton N, Waterhouse S, Lewis J, Girling C, Bradburn M, Arden MA, Whelan P, Ainsworth J, Dawson $\mathrm{S}$ et al: Real-world adherence among adults with cystic fibrosis is low - a retrospective analysis of the CFHealthHub digital learning health system. Chest 2021.

28. Quittner AL, Zhang J, Marynchenko M, Chopra PA, Signorovitch J, Yushkina Y, Riekert KA:

Pulmonary medication adherence and health-care use in cystic fibrosis. Chest 2014, 146(1):142-151.

29. Abrams EM, Szefler SJ: COVID-19 and the impact of social determinants of health. Lancet Respir Med 2020, 8(7):659-661. 
30. Marmot M: Social determinants of health inequalities. The Lancet 2005, 365(9464):1099-1104.

\section{Tables}

Table 1: Baseline characteristics of the study population

\begin{tabular}{|ll|}
\hline & No. $(\%)$ \\
\hline Age, med [IQR] & Total (N=725) \\
\hline Female & $28.0[20 \cdot 0 ; 37 \cdot 0]$ \\
\hline Occupation & $453(62 \cdot 5)$ \\
\hline Private sector & \\
\hline National or public company & $156(21 \cdot 7 \%)$ \\
\hline Self-employed & $26(17 \cdot 5 \%)$ \\
\hline Seeking a first job & $17(2 \cdot 4 \%)$ \\
\hline Seeking a job (have already work) & $46(6 \cdot 4 \%)$ \\
\hline Retired & $12(1 \cdot 7 \%)$ \\
\hline Homemaker & $60(8 \cdot 3 \%)$ \\
\hline Student (including high school) & $203(28 \cdot 2 \%)$ \\
\hline Other & $74(10 \cdot 3 \%)$ \\
\hline
\end{tabular}

Table 2: Use of care by cystic fibrosis (CF) patients during the first lockdown period 


\begin{tabular}{|c|c|}
\hline & No. (\%) \\
\hline Scheduled consultation in CF centre during lockdown period & $414(57 \cdot 7)$ \\
\hline Cancelled by patient & $20(4 \cdot 8)$ \\
\hline Cancelled by the hospital (no rescheduling or telehealth offered) & $40(9 \cdot 7)$ \\
\hline Telehealth offered by the hospital but refused by patient & $4(1 \cdot 0)$ \\
\hline Telehealth offered by the hospital and accepted by patient & $165(39 \cdot 9)$ \\
\hline Postponed with new appointment at the hospital & $111(26 \cdot 8)$ \\
\hline Maintained in-person at the hospital & $102(24 \cdot 6)$ \\
\hline Scheduled physiotherapy sessions & $333(46 \cdot 5)$ \\
\hline Cancelled by patient & $95(28 \cdot 5)$ \\
\hline Cancelled by the physiotherapist-no telehealth/online program offered & $90(27 \cdot 0)$ \\
\hline Online program offered by the physiotherapist and accepted by patient & $7(2 \cdot 1)$ \\
\hline Telehealth offered by the physiotherapist and accepted by patient & $11(3 \cdot 3)$ \\
\hline Telehealth or program offered by the physiotherapist and refused by patient & $4(1 \cdot 20)$ \\
\hline Postponed with new appointment at the hospital & $34(10 \cdot 2)$ \\
\hline Maintained at home or physiotherapist office & $115(34 \cdot 5)$ \\
\hline Scheduled annual review in CF centre during lockdown period & $105(14 \cdot 7)$ \\
\hline Cancelled by patient & $5(4 \cdot 8)$ \\
\hline Cancelled by the hospital (no rescheduling or telehealth offered) & $21(20 \cdot 0)$ \\
\hline Telehealth offered by the hospital but refused by patient & $0(0 \cdot 0)$ \\
\hline Telehealth offered by the hospital and accepted by patient & $15(14 \cdot 3)$ \\
\hline Postponed with new appointment in-person at the hospital & $56(53 \cdot 3)$ \\
\hline Maintained at the hospital & $13(12 \cdot 4)$ \\
\hline Hospitalisation required during the lockdown & $48(6 \cdot 7)$ \\
\hline Replaced by day hospital & $4(8 \cdot 3)$ \\
\hline Performed in another unit (not CF centre) & $7(14 \cdot 6)$ \\
\hline Postponed & $6(12 \cdot 5)$ \\
\hline Maintained & $33(68 \cdot 8)$ \\
\hline Intravenous antibiotic required during the lockdown & $66(9 \cdot 2)$ \\
\hline
\end{tabular}




\begin{tabular}{|l|l|}
\hline Performed at home & $51(77 \cdot 3)$ \\
\hline Replaced by oral antibiotic treatment & $2(3 \cdot 0)$ \\
\hline Postponed & $0(0 \cdot 00)$ \\
\hline Performed at hospital & $19(28 \cdot 8)$ \\
\hline Hospitalisation required during the lockdown & $48(6 \cdot 7)$ \\
\hline Replaced by day hospital & $4(8 \cdot 3)$ \\
\hline
\end{tabular}

Table 3: Verbatim from 9 representative patient's interviews. I1: LMC, F 26 yo; I2: UC, M, 52 yo; I3: LMC, 59 yo; 14: UC, F,16 yo; I5: UC, M,18 yo; 16: LMC, F, 31 yo; I7: PC, F, 17 yo; I8: UMC, F, 27 yo; 19: LMC, F, 38 yо; I13: UC, F, 50 yo; I: Interview, F: female, M: male; yo: years old, PC: Popular category; LMC: Lower middle category; UMC: Upper middle category; UC: Upper category.

Colour code: dark grey, PC; light grey, LMC; very light grey, UMC; and white, UC 


\section{Theme A: In relation to the medical institution}

A1: "I had called the physio's office and it actually went to voicemail and I listened to the voicemail, they said the office was going to be closed [during Lockdown]" (17).

A2: "I did some research [on the impact of covid-19 on cystic fibrosis], but in fact didn't find any...I went on the Internet...but I couldn't find any information, so I was disappointed" (17).

A3: "At the beginning, I must admit that I felt a bit lost, in the sense that our doctors did not call us to tell us what we had to do, how we were going to protect ourselves, plus, at the beginning, we did not have a mask... I'm married, so, my husband, what can he do, can he go out shopping or not, can he maybe be near others or not, knowing that if he catches the virus and brings it home and I get it...how does it work finally, me, well, I was a little bit confused at first" (19).

A4: "He told me that it was really serious, that I should be careful, that I shouldn't go out, that it was necessary for someone to go shopping for me, but afterwards, well, we didn't go into as much detail on the subject because they were really busy during that time, which I can understand, so they don't have a lot of time to devote to us, we can't stay on the phone for an hour, to get many explanations, so, well, that was okay, at first" (19).

A5:"There were planned [consultations] during the confinement, but in the end everything was cancelled, on the one hand, on my side. I didn't feel like coming to the hospital, I was afraid. The anxiety was terrible. Afterwards, I was offered telephone calls, so it was more convenient for me and for them too. It allows you to have follow-ups, so it also reassured me in that sense. And now [after deconfinement], I have face-to-face appointments again. " (I15)

A6:"I had questions, I asked them... he answered on a medical level, he was really available, any time, me, sometimes I sent emails in the middle of the night, yes because I had questions" (16).

A7: "I went to a lot of different hospitals because I rebelled a little bit, I didn't agree at all with the care, it didn't suit me" (16).

A8: "I decided after two weeks... I said stop the TV because you're going to go crazy... one never learns things from the news... I told my pulmonologist, 'Listen to me, I'm referring to you, so if there are things you think I need to know, you have to tell me"' (16)

A9: "And so it reassured her that I knew how to take care of myself, she reassured me about my own competence by telling me that I shouldn't worry because I was managing my own care by myself etc." $(16)$

A10: "And then, I contacted my CRCM by email saying, well, I don't understand, we haven't heard any news, so I was a bit panicked in fact, saying, 'what's going on and what in fact are we doing? ". And so then I had my [coordinating] nurse who got in touch with me and she told me that they had decided to respond to all requests but to answer only if we had questions and not to communicate with us if in fact we didn't have any. " (16)

A11: "here, they told me that it's here that you cancel all medical appointments and uh I didn't uh really understand because in fact, I told him, but uh you cancel all appointments, but then how were we going to do it really and at the time in fact one was not doing remote conferencing really, it was not even possible in the medical field, in fact it was always necessary to move and me, I am already nearby now and I always had to go to Foch etc. There was nothing done by remote conference, and so uh she tells me uh now we cancel here, you seem stable uh in relation to the information I was giving her... " (16)

A12: "Exactly, um, in no case, um I don't know if the other patients of Foch um [her centre], formulate it as I do, in no case do we feel abandoned by the medical staff, never, and that's important. " (I13)

A13: "It's true that I was very anxious because of my profession... how was it going to go, how was I going to manage... I had called the CRCM several times... to ask them, already before 16 March, if I 
A14: "It's true that my doctors... told me that there had been a few cases of CF who had had covid, that it hadn't been as severe as that... that they hadn't developed serious forms, so it's true that that reassured me" (18).

A15: "Well, as time goes by, this question is always present because, um, knowing whether we will develop more severe symptoms quickly. It's true that it's frightening, it accentuates the anxiety" (18)

A16: "a WhatsApp group where the doctor sent messages basically to parents and patients... with the latest information. It's always been quite reassuring, the most important feedback I got was that there were a hundred (patients) CF who had ... been infected and about ten who were in, there were no deaths, as far as I know, and a dozen or so ended up in intensive care... but all the intensive care where the people for whom the coronavirus was a problem were patients who had had transplants ... so we weren't told about the coronavirus as a threat specifically to cystic fibrosis" (I5).

A17: "my doctor used to tell all his patients 'seeing the state of information on this pandemic, here's what to do, here's what not to do, and if you have a concern, here's the person to contact"' (I2).

A18: "she distributed information... it's mostly by e-mail that I receive information... how to deal vis-avis your work, under what conditions you yourself could stop, if in terms of work, working from home was not possible... some information on hygiene measures, masks, how you could get them" (I2).

\section{Theme B: From physiotherapy to physical and sports activities: In relation to the body}

B1: "I'm still very independent in this respect, so I know how to do my physiotherapy, I know how to take care of myself, I took care of myself for two months without any problem, but I must admit that at the end of two months, I still needed to see my physiotherapist again, if only for the purpose finally to reassure myself, the fact that he [her physiotherapist] comes and tells me, 'It's OK, you've done your physiotherapy well', it's more for me, to reassure me" (19).

B2: "What I told myself is that yoga is pretty good, it's an activity that's not hyper physical and at the same time it's based on breathing, so I said to myself that maybe it could do me some good and um then the fact of breathing well could also take away, if you have anxieties, some anxieties, finally, it can in fact calm the body and the mind. So I started from that principle, saying to myself that in any case it could be good for me."(19)

B3: "It's all going to be fine now [interview conducted after deconfinement] with these physiotherapy sessions. But effectively, not having a physiotherapist, not being able to do the exercise rehabilitation sessions with the equipment like at the physiotherapist's, and then to have gained weight at the same time, it was a bit difficult" (113).

B4: "Sports is physical activity, it's also a moment I spend with other people. So then [during the confinement], I wasn't moving, and I was all alone" (11).

B5: "I contacted my physiotherapist, she gave me some tips on how to do sports in the garden, a bit anywhere. I followed her advice, it's fun at first, but you quickly let the rhythm go" (115).

B6: "So in fact I started to do quite a lot of sports and above all to surpass myself in fact ... so I did quite a lot of sports... I followed quite a few live streams in fact, from people who did, who before, did things for a fee, for example, yoga and things like that, and me, I took advantage of this, in fact, to enrich myself with a lot of things that I would have loved to do but that in fact usually either you have to travel for or pay a certain amount of money for etc....and so I decided to eat up as many things as possible that I wanted... it was brilliant" (16).

B7: "So at the beginning, um, there we were, we went on a bit of a tour, um, all together, nibbling in front of the TV, um, there we were. So um it's true that at the beginning we um it was a bit of a mess at 
home. I don't go to a gym because, um, I'd have to be followed by a coach etc. And then, well, it's not cheap either, so um, so no gym, um, I walk. And um during the confinement, zero sports to be honest, zero sports and um and then um not long ago I started cycling a bit again, the stationary bike... ". (113)

B8: "So yes, in my spare time, before the confinement, I used to do contemporary dance. Otherwise, I've always been a bit sporty, so I like running, sports, I don't stop doing sports because I love it. " (115)

B9: "Yes, so we used to do sports um at home, whether it was with my mother or just me on my own, um and plus as the weather was good and we had a garden, it's true that it was nice so we could be outside. So yes, I...I continued at home, um and it's true that we also used small equipment such as elastics or weights and all that. So it's true that it allowed us to keep uh to keep up an activity in fact, to have classes anyway so uh no on that, it was also in the end uh finding a rhythm that helped. "(I8)

B10: 'I started (sports) again with a friend who wanted to get back into it and that's it, we'd meet every other day at 4pm, we'd do sports for an hour, an hour and a half... on Skype... it wasn't anything that required going outside, we were in our respective rooms' (15). 


\section{Theme C: psychosocial adjustment to COVID-19 pandemic and associated lockdown measures}

C1: "Interviewee: Yes, we talk to them often, we even created a WhatsApp group so that we can keep in touch and everything, but with the confinement, as there are people who also have pathologies, we can't all see each other in fact. " (17)

C2: "So I said to myself, frankly, what I should do is not go out because I don't really have any information, especially as they said that those who... those who have a lung disease are already at risk of it being complicated for them with the coronavirus. (17)

C3: "I wash my hands quite a lot but [with covid-19], I washed my hands all the time, all the time, as soon as I touched something that came from outside, like the mail, a parcel, in fact I spent my life washing my hands" (19)

C4: "I kept telling my husband, when he went out, 'you put your mask on, you took your mask, you took your alcohol gel'... I kept telling him, 'don't forget to wash your hands as soon as you touch a door handle, there you go, then you use your alcohol gel". (19).

C5: "I say to myself, they don't understand the message, so there comes a time when you can't be in conflict all the time, you can't try to change people's lives, so I just let it go, the problem is that I think it isolates me" (19)

C6: "I didn't want to go to the pharmacy because I said to myself, maybe there are sick people coming to get their medicine... I didn't want my husband to go either because it was tricky, so the pharmacist was very nice and very accommodating... I sent her my prescription by email and then she came to deliver my medicine to my house" (19)

C7: "The problem is that sometimes what I reproach people for is that they manage to make me feel guilty, in fact, um, I know that my father-in-law wanted to come to the house even during the lockdown. He wanted to come to the house for a drink etc, so I told him no and I could see that he wasn't happy and that... so the problem is that it makes me feel guilty because I say to myself, um well I'm, I'm in... I'm the bad guy. I'm the bad guy, I tell him not to come, so because of me he doesn't see his son, um, so in a way it's not nice, well... that's how I experienced it anyway. " (19).

C8 : "my mother took it upon herself to be exposed to the virus (notably because she was in charge of doing the shopping for her, her daughter and her grandson), in fact, so when she returned home, potentially, we had to wait a fortnight to be sure ... well, that's what my pulmonologist used to tell me, to make sure that no one got it, so in fact, each time it necessitated pushing back on when I could see my son, so it lasted a very long time, and then he (the pulmonologist) started talking to me about the fact that in fact there was no end date for knowing when I would see my son again (...) as my pulmonologist used to say, it was that you had to wait until you had the tests" to see your son again (16)

C9: "basically, I had to do everything I had forbade myself to do during, for my part, over two and a half months" (16).

C10: "at the pharmacy, we are in contact with a lot of sick people, so I'm going to wait for the [contamination]rate to decrease a little"(I1).

C11: "I already know that I am very vulnerable, very fragile, so I did not go out as soon as the lockdown was announced. " (115)

C12: "No, I don't go out in public places. Ok so, I can walk my dog but I don't go out to places where I can meet people, it still scares me in any case. "(I15)

C13: "we clean more, we clean between each patient, the equipment, also each time, I change my gown" (18).

C14: "Um, afterwards it's true that my doctors in [her centre] told me that uh there had been a few 
cases of CF who had uh COVID that it hadn't been as severe as it had been, that it was rather maintained, that it had not developed serious forms. So it's true that that reassured me, um, to be able to allow myself, um, it's true that so me, I live with my parents... " (I8)

C15: "we didn't put any more precautions than that or extreme precautions inside the house, it's just maybe that we had less contact but that's all" (18).

C16: "I said, 'well, it's not complicated, we all respect the lockdown... what we're going to do is have face-to-face aperitifs'. We're two houses side by side with a hedge that crosses between, so we made a plan of who's going into the courtyard of which house, and we each arrive with our table, our chairs, our bottle and our glass, and we don't share anything at all, and we limit ourselves to half an hour. So it was me who set this up, it lasted half an hour, we were very happy, it was Saturday evenings, the following Saturday, it lasted an hour, then it went on longer... and the seventy year old neighbour was very happy" (I2).

C17: "Nobody comes into my home [Laughs]... but otherwise, we go for a walk, so I go with my mask and everything, I don't touch anything, in the street I don't sit anywhere. When someone who doesn't have a mask passes by, I try to avoid them without appearing too hysterical either, but I'm really careful that... that when they talk to me, they have a mask, they have... in any case the people l agree to see are people who have good hygiene rules, who have known me since I was a child and who know what to do, wash their hands, put on a mask and everything. " (14)

Table 4: Anxiety and depression developed during lockdown period

\begin{tabular}{|llllll|}
\hline & Age & {$[14-18]$} & {$[18-25]$} & {$[25-35]$} & {$[\geq 35]$} \\
\hline Anxiety (GAD-7) & $\mathrm{N}=725$ & $\mathrm{~N}=117$ & $\mathrm{~N}=153$ & $\mathrm{~N}=223$ & $\mathrm{~N}=232$ \\
\hline No (0-4) & $\mathrm{N}=717$ & $\mathrm{~N}=114$ & $\mathrm{~N}=150$ & $\mathrm{~N}=223$ & $\mathrm{~N}=230$ \\
\hline Mild (5-9) & $408(56 \cdot 8)$ & $77(67 \cdot 5)$ & $85(56 \cdot 7)$ & $115(51 \cdot 6)$ & $131(57 \cdot 0)$ \\
\hline Moderate (10-14) & $186(25 \cdot 9)$ & $29(25 \cdot 4)$ & $37(24 \cdot 7)$ & $62(27 \cdot 8)$ & $57(24 \cdot 8)$ \\
\hline Severe (>15) & $81(11 \cdot 3)$ & $5(4 \cdot 4)$ & $18(12 \cdot 0)$ & $27(12 \cdot 1)$ & $31(13 \cdot 5)$ \\
\hline Depression (PHQ-9) & $43(6 \cdot 0)$ & $3(2 \cdot 6)$ & $10(6 \cdot 7)$ & $19(8 \cdot 5)$ & $11(4 \cdot 8)$ \\
\hline No (0-4) & $\mathrm{N}=720$ & $\mathrm{~N}=114$ & $\mathrm{~N}=151$ & $\mathrm{~N}=223$ & $\mathrm{~N}=232$ \\
\hline Mild (5-9) & $352(48 \cdot 9)$ & $63(55 \cdot 3)$ & $67(44 \cdot 4)$ & $98(44 \cdot 0)$ & $124(53 \cdot 5)$ \\
\hline Moderate (10-14) & $215(29 \cdot 8)$ & $30(26 \cdot 3)$ & $33(21 \cdot 9)$ & $75(33 \cdot 6)$ & $77(33 \cdot 2)$ \\
\hline Moderately severe (15-19) & $32(4 \cdot 4)$ & $2(1 \cdot 8)$ & $13(8 \cdot 6)$ & $8(3 \cdot 6)$ & $9(3 \cdot 9)$ \\
\hline Severe (>20) & $105(14 \cdot 6)$ & $18(15 \cdot 8)$ & $33(21 \cdot 9)$ & $35(15 \cdot 7)$ & $19(8 \cdot 2)$ \\
\hline
\end{tabular}

Participants were asked to complete the 7-Item Generalized Anxiety Disorder Scale (GAD-7)[12] and the validated French version of 9-item Patient Health Questionnaire Depression Scale (PHQ-9)[13, 14].The total GAD-7 score ranges from 0 to 21, with a cut off of 10 indicating the presence of significant anxiety 
symptoms. GAD-7 scores of 5, 10, and 15 represent cut-off points for mild, moderate, and severe anxiety, respectively. The PHQ-9 score is composed of nine depressive symptom items listed in the Diagnostic and Statistical Manual of Mental Disorders-4th edition (DSMIV) for depression and ranges from 0 to 27[13]. PHQ-9 scores of 5, 10, 15, and 20 represent cut-off points for mild, moderate, moderately severe, and severe depression, respectively[13]. Numbers in brackets refer to percentage

Table 5: Impact of COVID-19 Pandemic and Associated Lockdown Measures on treatment, alcohol and smoking behaviours 
Age (years)

\begin{tabular}{|c|c|c|c|c|c|c|c|}
\hline & & Total & $\begin{array}{l}{[14-} \\
18]\end{array}$ & $\begin{array}{l}{[18-} \\
25]\end{array}$ & [25-35] & {$[\geq 35$} & p-value \\
\hline & & $\begin{array}{l}N= \\
725\end{array}$ & $\mathrm{~N}=117$ & $N=153$ & $N=223$ & $\mathrm{~N}=232$ & \\
\hline & & $N(\%)$ & $\mathrm{N}(\%)$ & $\mathrm{N}(\%)$ & $\mathrm{N}(\%)$ & $N(\%)$ & \\
\hline \multirow[t]{3}{*}{$\begin{array}{l}\text { Smoking } \\
\text { behaviours }\end{array}$} & Initiate/Increase & $\begin{array}{l}10 \\
(28 \cdot 6)\end{array}$ & $0(0 \cdot 0)$ & $\begin{array}{l}2 \\
(22 \cdot 2)\end{array}$ & $\begin{array}{l}6 \\
(40 \cdot 0)\end{array}$ & $\begin{array}{l}2 \\
(22 \cdot 2)\end{array}$ & 0.94 \\
\hline & Stable & $\begin{array}{l}12 \\
(34 \cdot 3)\end{array}$ & $\begin{array}{l}1 \\
(50 \cdot 0)\end{array}$ & $\begin{array}{l}3 \\
(33 \cdot 3)\end{array}$ & $\begin{array}{l}4 \\
(26 \cdot 7)\end{array}$ & $\begin{array}{l}4 \\
(44 \cdot 4)\end{array}$ & \\
\hline & Decrease/Stop & $\begin{array}{l}13 \\
(37 \cdot 1)\end{array}$ & $\begin{array}{l}1 \\
(50 \cdot 0)\end{array}$ & $\begin{array}{l}4 \\
(44 \cdot 4)\end{array}$ & $\begin{array}{l}5 \\
(33 \cdot 3)\end{array}$ & $\begin{array}{l}3 \\
(33 \cdot 3)\end{array}$ & \\
\hline \multirow[t]{3}{*}{$\begin{array}{l}\text { Alcohol } \\
\text { behaviours }\end{array}$} & Initiate/Increase & $\begin{array}{l}64 \\
(16 \cdot 4)\end{array}$ & $0(0 \cdot 0)$ & $\begin{array}{l}10 \\
(9 \cdot 4)\end{array}$ & $\begin{array}{l}20 \\
(15 \cdot 8)\end{array}$ & $\begin{array}{l}34 \\
(23 \cdot 5)\end{array}$ & 0.04 \\
\hline & Stable & $\begin{array}{l}150 \\
(38 \cdot 4)\end{array}$ & $\begin{array}{l}5 \\
(38 \cdot 5)\end{array}$ & $\begin{array}{l}41 \\
(38 \cdot 7)\end{array}$ & $\begin{array}{l}49 \\
(38 \cdot 6)\end{array}$ & $\begin{array}{l}55 \\
(37 \cdot 9)\end{array}$ & \\
\hline & Decrease/Stop & $\begin{array}{l}177 \\
(45 \cdot 3)\end{array}$ & $\begin{array}{l}8 \\
(61 \cdot 5)\end{array}$ & $\begin{array}{l}55 \\
(51 \cdot 9)\end{array}$ & $\begin{array}{l}58 \\
(45 \cdot 7)\end{array}$ & $\begin{array}{l}56 \\
(38 \cdot 6)\end{array}$ & \\
\hline \multirow[t]{3}{*}{$\begin{array}{l}\text { Psychotropic } \\
\text { Medications }\end{array}$} & Initiate/Increase & $\begin{array}{l}26 \\
(34 \cdot 7)\end{array}$ & $0(0 \cdot 0)$ & $\begin{array}{l}1 \\
(20 \cdot 0)\end{array}$ & $\begin{array}{l}9 \\
(42 \cdot 9)\end{array}$ & $\begin{array}{l}16 \\
(37 \cdot 2)\end{array}$ & 0.02 \\
\hline & Stable & $\begin{array}{l}41 \\
(54 \cdot 7)\end{array}$ & $\begin{array}{l}4 \\
(66 \cdot 7)\end{array}$ & $\begin{array}{l}3 \\
(60 \cdot 0)\end{array}$ & $\begin{array}{l}8 \\
(38 \cdot 1)\end{array}$ & $\begin{array}{l}26 \\
(60 \cdot 5)\end{array}$ & \\
\hline & Decrease/Stop & $\begin{array}{l}8 \\
(10 \cdot 7)\end{array}$ & $\begin{array}{l}2 \\
(33 \cdot 3)\end{array}$ & $\begin{array}{l}1 \\
(20 \cdot 0)\end{array}$ & $\begin{array}{l}4 \\
(19 \cdot 1)\end{array}$ & $1(2 \cdot 3)$ & \\
\hline \multirow[t]{3}{*}{ Sleep disorders } & Initiate/Increase & $\begin{array}{l}254 \\
(59 \cdot 5)\end{array}$ & $\begin{array}{l}27 \\
(57 \cdot 5)\end{array}$ & $\begin{array}{l}61 \\
(66 \cdot 3)\end{array}$ & $\begin{array}{l}81 \\
(56 \cdot 3)\end{array}$ & $\begin{array}{l}85 \\
(59 \cdot 0)\end{array}$ & 0.034 \\
\hline & Stable & $\begin{array}{l}146 \\
(34 \cdot 2)\end{array}$ & $\begin{array}{l}17 \\
(36 \cdot 2)\end{array}$ & $\begin{array}{l}24 \\
(26 \cdot 1)\end{array}$ & $\begin{array}{l}51 \\
(35 \cdot 4)\end{array}$ & $\begin{array}{l}54 \\
(37 \cdot 5)\end{array}$ & \\
\hline & Decrease/Stop & $\begin{array}{l}27 \\
(6 \cdot 3)\end{array}$ & $\begin{array}{l}3 \\
(6 \cdot 38)\end{array}$ & $7(7 \cdot 6)$ & $\begin{array}{l}12 \\
(8 \cdot 3)\end{array}$ & $5(3 \cdot 5)$ & \\
\hline \multirow[t]{3}{*}{ Compliance } & $\begin{array}{l}\text { Good } \\
\text { compliance }\end{array}$ & $\begin{array}{l}147 \\
(21 \cdot 1)\end{array}$ & $\begin{array}{l}17 \\
(15 \cdot 6)\end{array}$ & $\begin{array}{l}23 \\
(15 \cdot 3)\end{array}$ & $\begin{array}{l}33 \\
(15 \cdot 3\end{array}$ & $\begin{array}{l}74 \\
(33 \cdot 5)\end{array}$ & $<0.0001$ \\
\hline & $\begin{array}{l}\text { Minor } \\
\text { noncompliance }\end{array}$ & $\begin{array}{l}372 \\
(53 \cdot 5)\end{array}$ & $\begin{array}{l}59 \\
(54 \cdot 1)\end{array}$ & $\begin{array}{l}89 \\
(59 \cdot 3)\end{array}$ & $\begin{array}{l}121 \\
(56 \cdot 0)\end{array}$ & $\begin{array}{l}103 \\
(46 \cdot 6)\end{array}$ & \\
\hline & Noncompliance & $\begin{array}{l}177 \\
(25 \cdot 4)\end{array}$ & $\begin{array}{l}33 \\
(30 \cdot 3)\end{array}$ & $\begin{array}{l}38 \\
(25 \cdot 3)\end{array}$ & $\begin{array}{l}62 \\
(28 \cdot 7)\end{array}$ & $44(19 \cdot 9)$ & \\
\hline
\end{tabular}

\section{Figures}



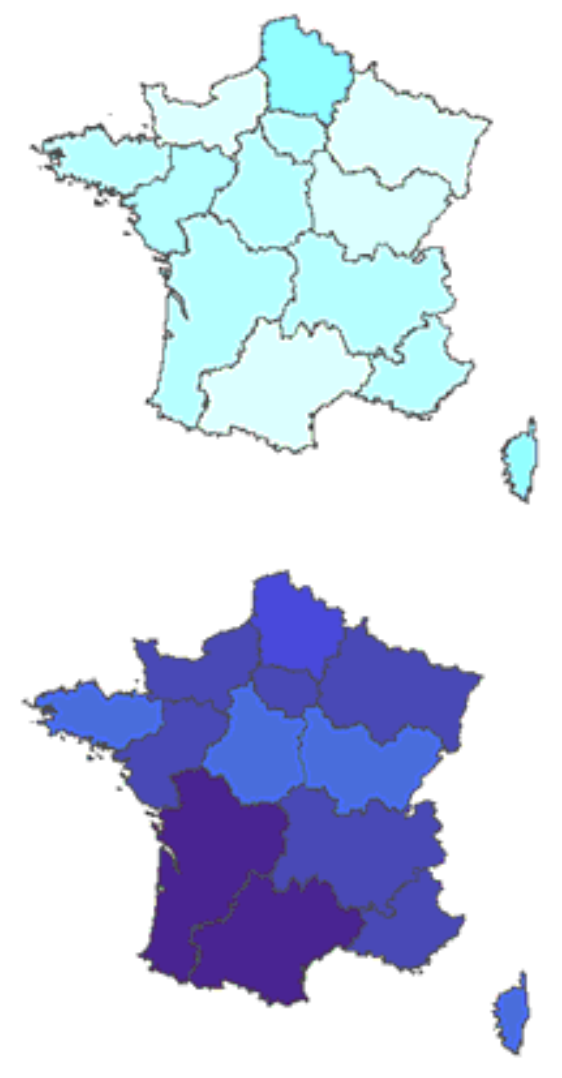

COVID-19 dangerous for me $/ 10$
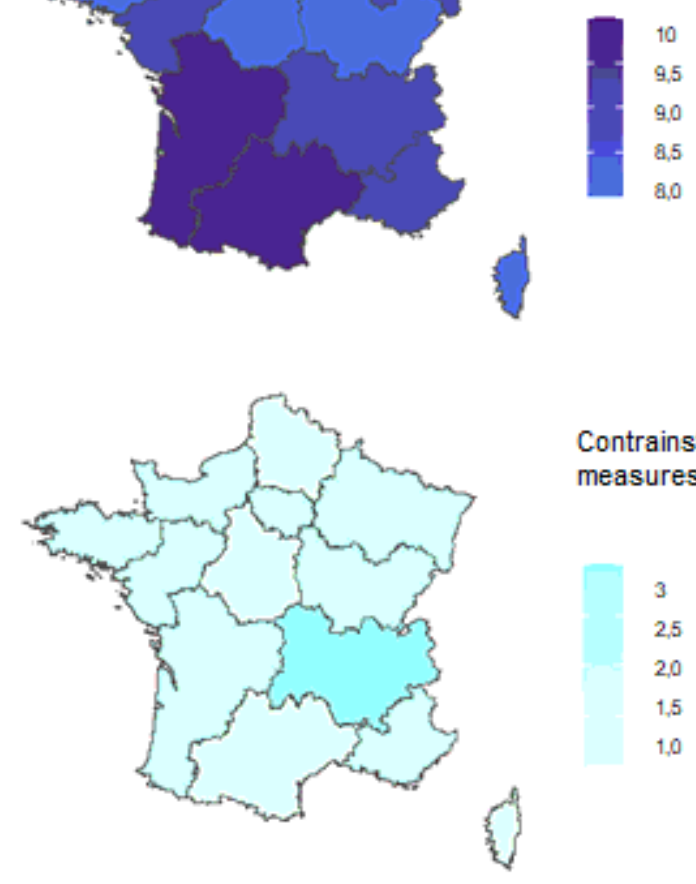

Contrainst of barrier measures $/ 10$
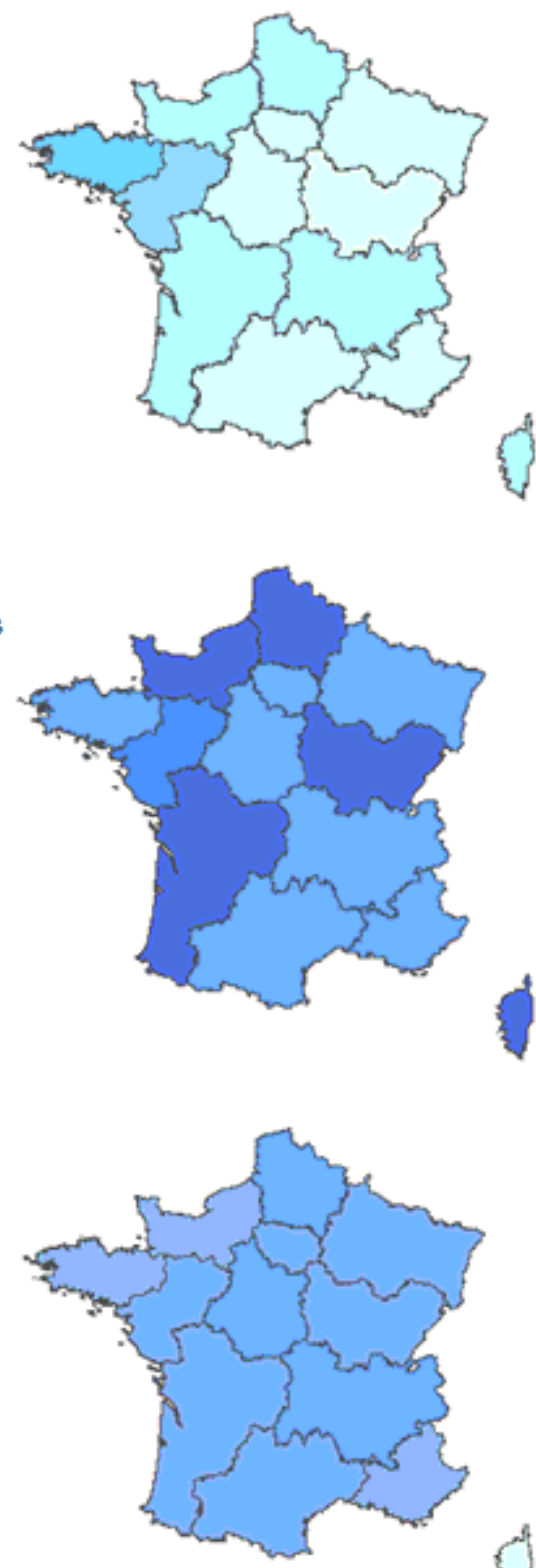

Median depression score

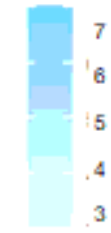

COVID-19 dangerous for relatives $/ 10$

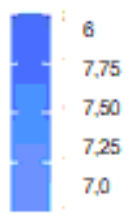

Contrainst of lockdown $/ 10$

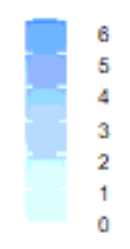

Figure 1

Health impact of the COVID-19 epidemic and associated lockdown measures on cystic fibrosis patients during the first wave of COVID- 19 according to different geographic regions of France. Assessment of anxiety and depression: participants were asked to complete the 7-Item Generalized Anxiety Disorder Scale (GAD-7)[12] and the validated French version of the 9-item Patient Health Questionnaire Depression Scale (PHQ-9) $[13,14]$. The total GAD-7 score ranges from 0 to 21 , with a cut off of 10 indicating the presence of significant anxiety symptoms. The PHQ-9 score is composed of nine depression symptom items listed in the Diagnostic and Statistical Manual of Mental Disorders-4th edition (DSMIV) for depression and ranges from 0 to 27[13]. The median score is indicated for each metropolitan French geographic area. "COVID-19 dangerous for me", "COVID-19 dangerous for relatives", constraints from barrier measures, and constraints from lockdown were assessed using a scale of 1 to 10, with 1 being "very low " and 10 being "very high". Results are represented for each of the French geographic areas, with 
colours that correspond to the values in an intuitive manner (higher values are darker blue, while lower values are lighter blue)

\section{Supplementary Files}

This is a list of supplementary files associated with this preprint. Click to download.

- FigureS11.tif

- Figures2.tif

- supplementarytable.docx

- SUPPLEMENTARYFILESLEGEND.docx 